\title{
AQUISIÇÃO DA LEITURA E ESCRITA NA EDUCAÇÃO INFANTIL
}

\author{
Kelly Andre de Almeida Caraìba ${ }^{1}$ \\ Prof. Dr. Márcio Wendel Santana Coêlho²
}

\begin{abstract}
RESUMO
A Educação Infantil ao longo do tempo vem se modificando, rompendo com o assistencialismo e abraçando uma educação que tem como premissa educar e cuidar, lançando um novo olhar para a aprendizagem da criança. Saber ler e escrever com competência é uma prerrogativa necessária para o exercício da cidadania. Por compreender que há necessidade aproximar a criança do mundo letrado de forma prazerosa, com significado e visando sua promoção, o presente artigo tem como objetivo discutir sobre os processos de leitura e escrita na educação infantil a partir de uma abordagem qualitativa e bibliográfica. Traz alguns apontamentos sobre alfabetizar ou não nessa etapa de ensino sob a ótica das teorias de Ferreiro e Teberosky (1999), Brandão e Leal (2011), Soares (2000), bem como em documentos oficiais que regulamentam as práticas pedagógicas.
\end{abstract}

PALAVRAS-CHAVE: Educação Infantil; Leitura; Escrita

\begin{abstract}
A long-standing Early Childhood Education is changing, breaking with assistance and embracing an education that has as its premise to educate and care, taking a new look at children's learning. Learn to write about competition and a necessary prerogative for the exercise of citizenship. Understanding that there is a need to bring children closer to the literate world in a pleasurable way, with meaning and aiming at their promotion, this article aims to discuss the processes of reading and writing in early childhood education from a qualitative and bibliographic approach. It brings some notes on literacy or internship not in this teaching on the optics of the theories of Ferreiro and Teberosky (1999), Brandão and Leal (2011), Soares (2000), 2), according to official documents that regulate pedagogical practices. I intend to present an understanding of the literacy process in early childhood education.
\end{abstract}

KEYWORDS: Early Childhood Education; Reading; Written

\footnotetext{
${ }^{1}$ Mestre em Ciências da Educação. Especialista em Psicopedagogia Institucional, clínica e Hospitalar. Licenciada em Pedagogia. E-mail: kellycaraibas@yahoo.com.br

2Pós Doutor em Neuropsicologia Clínica Hospitalar, Doutor em Ciências da Saúde \& Psicanálise Clínica, Doutor em Ciências da Educação, Mestre em Ciências da Educação, Licenciado em Pedagogia, Especialista em Gestão Escolar com Ênfase em Psicologia Escolar, Especialista em Pedagogia Hospitalar. E-mail: doutorwendel2015@gmail.com
} 


\section{RESUMEN}

Una Educación Infantil de larga data está cambiando, rompiendo con la asistencia y abrazando una educación que tiene como premisa educar y cuidar, se dio una nueva mirada al aprendizaje de los niños. Aprenda a escribir sobre la competencia y una prerrogativa necesaria para el ejercicio de la ciudadanía. Entendiendo que existe la necesidad de acercar a los niños al mundo alfabetizado de forma placentera, con sentido y con el objetivo de promoverlos, este artículo tiene como objetivo discutir los procesos de lectura y escritura en la educación infantil desde un enfoque cualitativo y bibliográfico. Trae algunas notas sobre alfabetización o prácticas no en esta enseñanza sobre la óptica de las teorías de Ferreiro y Teberosky (1999), Brandão y Leal (2011), Soares (2000), según ocumentos oficiales que regulan las prácticas pedagógicas. Tengo la intención de presentar una comprensión del proceso de alfabetización en la educación infantil.

PALABRAS CLAVE: Educación Infantil; Leer; Escrito

\section{INTRODUÇÃO}

Do ponto de vista da ciência que estuda o desenvolvimento humano, a infância é o período de crescimento que vai do nascimento até a puberdade. A ideia de infância é uma noção historicamente construída, que sofre influências legais, culturais e, portanto, tem se modificado conforme as formas de organização da sociedade.

Parte desse pressuposto a necessidade de ter uma educação escolar para as crianças. Durante muito tempo as instituições destinadas a esse fim viam a criança como um ser carente e imaturo, por este motivo os ensinamentos para prepará-la ao convívio social era do adulto.

Baseados em estudos realizados por correntes como a psicologia, sociologia, história e antropologia, a criança começa a ser vista com outro olhar. Há uma ruptura com concepções tradicionais em relação a natureza infantil. Passaram a considerar a criança como cidadão único, singular e produtor de cultura.

Haja vista que na sociedade contemporânea ler e a escrever é um patrimônio cultural e é de extrema importância que todos tenham acesso, a escola de Educação Infantil não pode se negar a assumir o seu papel de mediadora entre o conhecimento da criança e a cultura letrada.

O ensino da leitura e escrita na educação infantil tem levantado discussões acirradas entre educadores, uns estão preocupados com a escolarização ao se investir na aquisição da leitura e escrita, enquanto outros acreditam que a criança tem de ser alfabetiza nessa etapa. Diante dessas inquietações, é importante entender o que os professores pensam, quais suas concepções e suas práticas educativas para promover a aprendizagem. 
Portanto, este artigo parte de uma pesquisa realizada sobre a temática. Visa apresentar uma breve revisão de pesquisas que apontam concepções de leitura e escrita na educação infantil a luz das teorias de Ferreiro e Teberosky (1999), Oliveira (2002/2014), Brandão e Leal (2011), Soares (2004/2005/2013), Smolka (2012), bem como dos documentos oficiais LDB (1996), RCNEI (1998) e DCNEI (2010) que regulamentam as práticas pedagógicas. Ademais, traz algumas apontamentos sobre alfabetizar ou não nessa etapa de ensino, sob a ótica do educador, sua percepção enquanto elemento fomentador para a inserção da linguagem oral e escrita em consonância com cidadãos críticos e participativos. Pretendem-se com este estudo servir apresentar aos profissionais da educação, uma compreensão do processo de alfabetização na educação infantil.

\section{MÉTODOS}

Neste artigo, pretende-se delinear um estudo acerca da alfabetização em sala de aula, com o objetivo de compreender como se processa a leitura e escrita na educação infantil, por compreender que há necessidade aproximar a criança do mundo letrado de forma prazerosa, com significado para ela, visando promoção de todas as linguagens, oportunizando a apropriação das várias formas de se comunicar, constituindo a mesma em uma cidadã do mundo e para o mundo.

A partir desse pressuposto, a utilização dos aspectos qualitativos este estudo é bibliográfico, ao passo que apresenta um referencial teórico que discute o processo de leitura e escrita na Educação Infantil, as concepções pedagógicas. Implica no levantamento de elementos de várias fontes com o intuito de apresentar informações sobre o tema.

Assim sendo, essse processo metodológico possibilitará definir e sintetizar as discussões sobre as práticas de leitura e escrita na primeira infância.

\section{ANÁLISE E DISCUSSÃO}

Inúmeros questionamentos têm surgido no meio dos professores de educação infantil, se devemos ou não alfabetizar nessa etapa. Primeiramente precisamos compreender o sentido de alfabetizar e como essa criança aprende, como é construído seu conhecimento, sua autonomia. Para Seber (2010, p.12), "o caminho da autonomia intelectual é o do agir sobre a escrita com liberdade; aprendendo a ler 
e a escrever, a criança tem maior chance de dominar conceitualmente esse sistema representativo da língua".

Segundo Piaget a interação do indivíduo com o mundo exterior é o meio por onde o desenvolvimento intelectual humano acontece. $O$ professor e pesquisador russo Vygotsky, mostra que a aquisição do conhecimento se dar pela interação com o meio a partir da cultura do sujeito. Já Emília Ferreiro (1999), conclui que quanto maior for a interação com os modelos convencionais de escrita, maior ainda será a influência destes sob a construção do conhecimento. Todas essas produções científicas têm contribuído para um novo olhar no trabalho com as crianças, com o intuito de inserilas na cultura letrada.

A Educação Infantil, segundo Brandão e Leal (2011), é lugar de vivenciar práticas de leitura e escrita, sem que isso signifique desconsiderar suas necessidades e interesses. As diferentes linguagens (plástica, corporal, musical, faz de conta) podem conviver harmoniosamente com a linguagem escrita.

Até bem pouco tempo no Brasil e em especial no interior, compreendiam que a criança para ler e escrever teria que estar preparada, pronta, isso por volta dos seis a sete anos de idade. As tentativas de alfabetizá-las antes desse período, estariam fadadas ao fracasso e que as mesmas não tinham interesse na alfabetização. Brandão e Leal (Poppovic e Moraes,1996, p.5 apud Brandão e Leal, 2011, p.14), enfatiza que a prontidão na alfabetização precisa ter um nível suficiente, sob determinados aspectos, para iniciar o processo da função simbólica que é a leitura e sua transposição gráfica, que é a escrita.

Dessa forma a educação infantil deveria usar seus recursos para a aprendizagem vidando a preparação da criança, para posteriormente ler e escrever. Era importante e necessário concentrar seu trabalho nas habilidades de coordenação motora, percepção auditiva e visual, orientação espacial, boa alimentação, hábitos de higiene, entre outros.

Brandão e Leal (2011), enfatiza que essa concepção sobre leitura e escrita na educação infantil, influenciou diretamente os programas de políticas públicas para crianças em pré-escolas dos anos de 1970 e 1980, direcionando os trabalhos realizados no chão da sala de aula de todo o Brasil.

No entanto pesquisadores como Vygotsky (1984) já questionavam esses ensinamentos desde 1920. Segundo ele a criança tem a capacidade de descobrir a função simbólica da escrita e iniciar no mundo da leitura, antes dos seis anos de idade. Segundo Vygotsky apud Brandão e Leal (1940), a escrita precisaria ser ensinada como algo relevante para a vida, pois somente dessa forma ela se desenvolveria não como hábito de mão e dedos, mas como uma forma nova e complexa de linguagem.

Para o autor a leitura e a escrita precisam ser ensinadas de uma forma que leve a criança a sentir necessidade de fazer uso delas, não deve ser de forma mecânica para não levar ao abuso, ao descrédito. Vygotsky (2010) tratando sobre o ensino da 
linguagem é categórico ao afirmar que "a leitura e a escrita deve ser algo de que a criança necessite". Essa visão contrapõe ao que era ensinado pela maioria das escolas, uma escrita como habilidade motora, sem significado para as crianças. Vale ressaltar que muitos profissionais da educação comungavam das ideias de Vygotsky e criticavam a abordagem de prontidão para a alfabetização, que valorizava os exercícios repetitivos e as atividades onde o recurso era simplesmente lápis e papel. Apesar dos investimentos pelo poder público em propagara o método do ensino preparatório, a alfabetização continuava fracassando.

Com tantos questionamentos em relação aos baixos índices de alfabetização na escola pública, foi aberto novos caminhos, novos métodos para o trabalho com a linguagem na educação infantil. Surgi então os que defendem um ensino na educação infantil que possibilite que a criança termine essa etapa alfabetizada ou bem próximo de ser. Brandão e Leal ressalta que:

Os que adotam esse modo de pensar defendem, portanto, que as crianças concluam a Educação Infantil já dominando certas associações grafofônicas, copiando letras, palavras e pequenos textos, bem como lendo e escrevendo algumas palavras e frases. $(2011$, p.16)

Os exercícios preparatórios se apresentam nessa visão com uma nova roupagem, agora a ênfase está nos treinos das letras e palavras. $O$ aprendizado tem início com o trabalho exaustivo de leitura, identificação e escrita das vogais, consoantes e famílias silábicas, para enfim chegar no reconhecimento e leitura de palavras e frases. Brandão e Leal (2011) nos alerta que o princípio de alfabetização dessa ideia está em dizer que "leitura e escrita correspondem à aquisição de um código de transcrição do escrito para o oral e vice-versa, bastando à criança memorizar as associações som-grafia para ser alfabetizada". As autoras chamam de "a obrigação da alfabetização".

Outro olhar sobre a educação infantil é o inverso desse mencionado anteriormente. Nesse há uma supervalorização de outras linguagens como a corporal, musical, plástica, dramática, diminuindo o ensino da linguagem escrita no trabalho com as crianças. Os que defendem essa ideia compreendem que leitura e escrita nessa etapa "é concebida como objeto do trabalho educativo, sendo, em geral, tomada como um "conteúdo escolar" e, portanto, proibido para crianças da Educação Infantil" (BRANDÃO E LEAL, 2011, p. 18).

Para as autoras é bastante positivo tratar na educação infantil sobre leitura e escrita, alfabetização e ensino. Esse pensamento também é compartilhado por Abramovay e Kramer, onde ressalta que:

A pré-escola tem, portanto, como papel fundamental em relação à alfabetização, garantir a compreensão por parte das crianças, do que é a leitura e a escrita e, ainda, favorecer a autoconfiança das crianças na sua capacidade de aprender a ler e escrever. (1985, p. 105) 
Portanto, compreendem que a linguagem escrita é uma expressão importante na pré-escola, e que é imprescindível elevar na criança a sua confiança, para que saibam que têm condições de aprender a ler e escrever.

É pertinente refletir sobre as práticas de alfabetização e letramento na Educação Infantil, avaliando se essas práticas são necessárias, se propicia o desenvolvimento humano, cultural, científico e tecnológico das crianças, os quais servem de suporte para enfrentar as exigências do mundo contemporâneo. Ou ainda se o que é proporcionado a elas, não somente ao da educação infantil como os da escolarização obrigatória, são exercícios de memorização e cópia de letras e famílias silábicas. Por outro lado, também não é interessante tolher a leitura e escrita da formação da criança, com o pretexto de que o "ensino" é um desrespeito a infância.

Os estudos de Emília Ferreiro e Ana Teberosky, inspira muitos educadores no Brasil e em outras partes do mundo. Aqui no Brasil seus estudos começaram a ser difundidos por volta da década 1980. Suas pesquisas levam a compreensão de como ocorre o processo de alfabetização segundo a criança. Essas pesquisadoras lançaram um novo olhar na interpretação da aquisição da escrita, do ponto de vista do aprendiz, da forma como ele entende a leitura e a escrita.

Outras modalidades de ensino, bem como a educação infantil, foram impactadas por seus ensinamentos, uma vez que as autoras defendem que as crianças têm a necessidade de serem imersas na cultura escrita desde os primeiros anos. Nessa visão a alfabetização ultrapassa fronteiras e pode/deve ser iniciada muito antes da escolarização.

Ferreiro e seus colaboradores chegaram à conclusão que as crianças pensam e formulam hipóteses sobre a escrita antes de serem alfabetizadas e que a interação com esta, não ocorre da mesma forma para todas as crianças. Ferreiro (1993, p.23) salienta que:

Há crianças que chegam à escola sabendo que a escrita serve para escrever coisas inteligentes, divertidas ou importantes. Essas são as que terminam de alfabetizar-se na escola, mas começaram a alfabetizar-se muito antes, através da possibilidade de entrar em contato, de interagir com a língua escrita.

Percebe-se então que a Educação Infantil tem a oportunidade de mediar o envolvimento das crianças com a escrita, em especial daquelas que só participam desses momentos na escola.

Partindo do pressuposto de que as crianças formulam diversas hipóteses de escrita e que gradativamente vai evoluindo, é interessante promover o contato com atividades e situações que estimule e faça refletir sobre o sistema alfabético de escrita e suas características. Contudo, é relevante salientar que a prática pedagógica deve 
incentivar a cultura escrita, respeitando a cultura infantil e a criança como produtora de cultura. Brandão e Leal (2011, p.21) enfatiza,

\footnotetext{
[...] que nesta faixa etária a brincadeira constitui-se atividade central do cotidiano infantil. É brincando que as crianças participam do mundo adulto e aprendem suas características. Brincando, elas podem, também, ingressar na cultura escrita. Em suma, propomos que, na Educação Infantil, sejam garantidas situações de convívio com a escrita, sem, no entanto, tornar tais vivências um fardo para as crianças.
}

Nesse sentido, o Referencial evidencia que uma aprendizagem significativa da língua, por meio de um trabalho com a linguagem oral e escrita, desenvolverá gradativamente as capacidades associadas às quatro competências linguísticas básicas: falar, escutar, ler e escrever, possibilitando o acesso da criança ao mundo letrado (RECNEI, 1998, v.3, p.117).

Ratificando o que aborda o referencial, destacamos nesse momento a importância das práticas de leitura, uma vez que é um dos meios mais importantes que os seres humanos encontram para entrarem em contato com o conhecimento, as emoções, a imaginação, o prazer e a interação entre os sujeitos e as culturas. E para que isso aconteça, como nos diz Carvalho (1997), há que se considerar a leitura de diferentes linguagens, como da linguagem verbal, visual, auditiva, olfativa, gustativa, bem como os gestos, os sons, os sentidos, as coisas, os traços, as linhas, a natureza, os comportamentos, a moda, a televisão, o cinema, o teatro, enfim, tudo o que é vivo e significativo.

A família e a escola têm o papel, a partir da educação infantil, de aproximar o aluno da leitura e da escrita, uma vez que para isso acontecer não é necessário a criança estar alfabetizada para ler na face da mãe o seu aborrecimento e a sua alegria, por exemplo.

Os professores de educação infantil cabem-lhes, o papel de mediador entre a criança a leitura e a escrita. Nos primeiros anos, a criança pode até não dominar os signos verbais, mas já processa uma variedade de textos, já possui certo nível de letramento. Conforme Soares (2000, p.47):

\footnotetext{
Uma criança que vive num contexto de letramento, que convive com livros, que ouve histórias lidas por adultos, que vê adultos lendo e escrevendo, cultiva e exerce práticas de leitura e de escrita: toma um livro e finge que está lendo (...), toma papel e lápis e "escreve" uma carta, uma história. Ainda não aprendeu a ler e escrever, mas é, de certa forma letrada, tem já certo nível de letramento.
}

É importante que nessa etapa de ensino, na educação infantil, a criança conviva com uma diversidade de textos e principalmente a literatura, que tem uma finalidade prazerosa, podendo formar leitores efetivos, assíduos para uma vida toda. A leitura dos diversos gêneros textuais é um momento que possibilita para a criança 
o conhecimento da forma de amar, viver, se emocionar, pensar, construir, desconstruir o agir de outras culturas, de outros tempos e lugares, bem como o universo de valores. Aprender a ler na infância é ler o mundo, é atribuir sentido e significado aos olhares, cheiros, afeto, sabores e saberes acumulados na vivência diária.

Valendo-se dessa compreensão, precisamos aproximar a criança do mundo da leitura e escrita em um ambiente prazeroso e que tenha significado para ela. No dia a dia da educação infantil, é necessário proporcionar momentos e atividades que venham promover todas as linguagens, oportunizando a apropriação das várias formas de se comunicar, facilitando a inserção no mundo letrado.

\section{CONSIDERAÇÕES FINAIS}

Em nossa sociedade a leitura e a escrita são essenciais e fazem parte do nosso cotidiano. Estar alfabetizado configura-se como uma importante ferramenta de poder, por possibilitar o ingresso das pessoas à cultura letrada. Avaliando as relações sociais de poder, compreende-se que a escola tem a responsabilidade de facilitar o acesso de todas as pessoas ao conhecimento.

Sendo a leitura e a escrita na Educação Infantil todo o processo de contato com sentido e significado em situações que envolva o ato de ler e escrever e de refletir sobe o sistema de escrita, cabe a escola proporcionar diversificados meios que envolva a cultura letrada.

A história da Educação Infantil no Brasil tem sido marcada por inúmeros avanços, na busca pelo rompimento com o assistencialismo e em direção a uma educação voltada para o pleno desenvolvimento da criança em seus aspectos físico, psicológico, intelectual e social, pautada na indissociabilidade entre os atos de cuidar e educar.

O desenvolvimento integral é relevante e para isso é importante que as crianças sejam desafiadas a resolver problemas e estimuladas a fazerem descobertas sobre si, o outro e o mundo a sua volta. Entendemos que a escola deve ser um espaço de múltiplas exigências, onde a criança tenha a oportunidade de conviver e fazer uso das mais diversas linguagens. Essa nova ótica compreende que desde pequenas as crianças têm o direito de ser iniciada no mundo letrado, uma vez que a escrita exerce grande fascínio sobre elas.

Portanto, a criança desde a educação infantil pode iniciar o seu processo de aprendizagem da leitura e escrita, cabe agora procurar a melhor maneira de iniciar a alfabetização. Não é aquela alfabetização preparatória, treinadora e repetitiva, mas, defendo uma alfabetização que envolva a criança em situações em que ela aprenda 
alguns princípios do sistema de escrita alfabética e inserindo-as nas práticas sociais em que a escrita está presente.

\section{REFERÊNCIAS}

BRASIL. Referencial Curricular para a Educação Infantil/Ministério da Educação e do Desporto, Secretaria de Educação Básica - Brasília: MEC, SEF. 1998. v. 3.

BRANDÃO, A. C. P. e LEAL, T. F. Alfabetizar e letrar na Educação Infantil: o que isso significa? In. BRANDÃO, A. C. P.; ROSA, E. C. de S. (Org.). Ler e escrever na educação infantil: discutindo práticas pedagógicas. Belo Horizonte: Autêntica, 2011.

CARAÍBA, Kelly Andre de Almeida. O Processo de Leitura e Escrita no Centro de Educação Infantil Gabriela Rodrigues Pimenta em Serra do Ramalho-Bahia. Dissertação de Mestrado em Ciências da Educação - Faculdad Interamericana de Ciências Sociales, na Cidade de Assunção - Paraguai, 2019.

FERREIRO, Emília; TEBEROSKY, Ana.Psicogênese da Língua Escrita. Porto Alegre: Artes Médicas Sul, 1999.

KRAMER, Sônia; ABRAMOVAY, Miriam. Alfabetização na pré-escola: exigência ou necessidade. Caderno de Pesquisa (52), São Paulo: Unicamp, 1985.

SEBER, Maria da Glória. A escrita Infantil - O caminho da construção. 1a edição. Ed. Scipione. São Paulo.2010.

SOARES, Magda. Letramento: um tema em três gêneros. 2.ed. Belo Horizonte: Autêntica, 2000.

VYGOTSSKY, Lev Semenovitch. A formação social da mente: O desenvolvimento dos processos Psicológicos Superiores. 3를. Ed. Paulo: Martins Fontes, 1989. 